\title{
Investigations on Three-Phase Grid-Connected Inverter using PWM Controllers
}

\author{
D. Manikanta Swamy, M. Venkatesan* and M. Subbarao \\ Vignan's Foundation for Science, Technology \& Research, Guntur, Andhrapradesh, India.
}

Received 5 July 2020; Accepted 19 October 2020

\begin{abstract}
In recent years, a Multilevel Inverter (MLI) topology is highly preferred in the various renewable energy applications for converting power due to their merits. In this paper, a three-phase inverter has been designed for grid-connected applications using Proportional Integral (PI) current controller scheme. To generate a sequence, the Level shift (LS) and Phase Shift (PS) Pulse Width Modulation (PWM) methodologies are adapted. This topology has been designed with two stages: the DC-DC conversion stage and DC-AC conversion stage. The DC-DC conversion stage is used to enrich input DC voltage which is obtained from the solar PV array. The PI current controller has been designed to regulate the grid current with park transformation. The performances of the inverter have been examined in terms of Total Harmonic Distortion (THD) using different PWM techniques and also investigated with existing research works. The developed results are verified using MATLAB/ Simulink.
\end{abstract}

Keywords: MLI, LS-PWM, PS-PWM, PI, THD, MLI.

\section{Introduction}

The development of high power converter topologies is growing day by day and multilevel inverters are being concentrated by researchers [1]. Particularly, MLI topologies are remarkably commended by researchers for high power applications due to their merits such as modular structure, lesser filtering requirements [2]. In [3], the authors have investigated different types of basic MLI topologies and also discussed various hybrid MLI topologies for RES applications. The MLIs can operate both a fundamental frequency $(50 \mathrm{~Hz})$ as well as high switching frequency $(\mathrm{kHz}$ ranges) [4]. Some of the few authors only concentrated and investigated the single dc source-based MLI instead of multiple dc sources and it is suitable for solar photovoltaic applications [5]. Even though MLIs topologies are applied in various industrial and research applications and control the inverter diversified PWM controller has been applied [6]. The different types of multi-carrier PWM techniques have been applied to the five inverters and also investigated phase shift control schemes [7]. The different PWM controllers have been investigated by the authors and also suggested to the modular MLI structure [8]. Recently, a Multi-Carrier PWM (MC-PWM) based modified MLIs have been proposed by minimizing the number of switching count [9]. In [10], 3-phase MLI topologies have been reported for high power applications using MC-PWM. The proposed topology is presented with less number of switches in comparison with $\mathrm{CHB}$. The $\mathrm{CHB}$ has modularity in structure. In this paper, the different types of modular structure have been discussed. So, the cost of design is significantly reduced with this type of inverters [11]. This paper deals with the various types of MLIs topologies using a reduced number of switching counts and also investigated

*E-mail address: drmvenkatesan_vlits@vignan.ac.in ISSN: 1791-2377 @ 2020 School of Science, IHU. All rights reserved. doi:10.25103/jestr.135.23 hybrid MLIs [12]. In [13] transformer based inverters have been presented for three-phase and single applications to help with the single dc sources and transformer. To inject the sinusoidal current into the grid, a different kind of closed controller is discussed [14]. In order to control the sinusoidal current, a PI-based current regulator is used in this inverter circuit. Multi-carrier PWM based modular MLI inverter for renewable energy applications is investigated using asymmetrical dc input [15]. From the discussion, it is clear that multi-carrier PWM techniques have been suitable for the control characteristics of modular MLI topologies. In this paper, different PWM controllers have been applied and tested.

\section{Three-Phase Five-level Inverter}

The Multilevel inverter is applied to control both the standalone and grid-connected applications with the help of various control methodologies. Number MLIs topologies have been discussed in the literature review and also noted limitations. The block diagram of the various PWM controlled three-phase MLI inverters is shown in Fig. 1. In this research work, there are two converters designed to converter RES power and transferred to the grid network. The output of the PV array is connected to the boost converter and it is used to match impedance to the inverter network. This work is normally achieved with the help of maximum power point tracking algorithms. In this $\mathrm{P} \& \mathrm{O}$ have been applied to extract the maximum power available from the Solar PV array. The second stage is used to generate a five-level output voltage of the DC bus and inject the power to the grid through a passive filtering network. The power circuit of the PWM controlled three-phase MLI and their operating modes are shown in Fig. 2 (a) and (b) respectively.

The suggested MLI for grid-connected applications has been a less number of power switches as similar to the other 
existing MLI topologies. This topology consists of five switches per phase, hence 15 -switches are required for making a three-phase system. Out of 5-switches, Sa1-Sa4 switches are forming $\mathrm{H}$ bridge inverters. The arrangement of Sa5 switches along with four diodes is called an auxiliary switch. In the suggested MLI switches Sa1, Sa 2, and $\mathrm{Sa} 5$ are operated at $20 \mathrm{kHz}$ frequency, the remaining two switches $\mathrm{Sa} 3$ and $\mathrm{Sa} 4$ are operated in the $50 \mathrm{~Hz}$ frequency. Table 1 indicates the comparison between the existing and suggested MLI topologies. Fig. 3 represents the output voltages and currents of the inverter with various Modulation Index (MI) values. Fig. $3(\mathrm{a}-\mathrm{c})$ are indicated the phase voltages of the inverter at $\mathrm{MI}=1.1,0.7$, and 0.4. Fig. 3 (d-f), indicates the phase currents of the inverter at $\mathrm{MI}=$ 1.1, 0.7, and 0.4. Fig. 3 (g), 3 (h), and 3 (i) represent the three-phase load voltages of the inverter at $\mathrm{MI}=1.1,0.7$, and 0.4 .

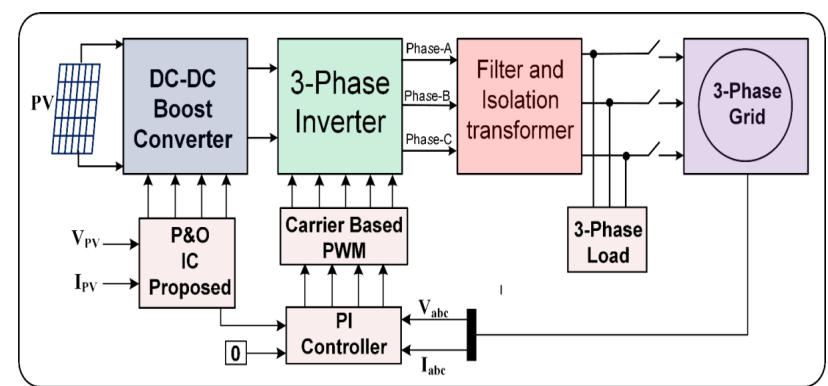

Fig. 1. Circuit diagram of the proposed MLI system

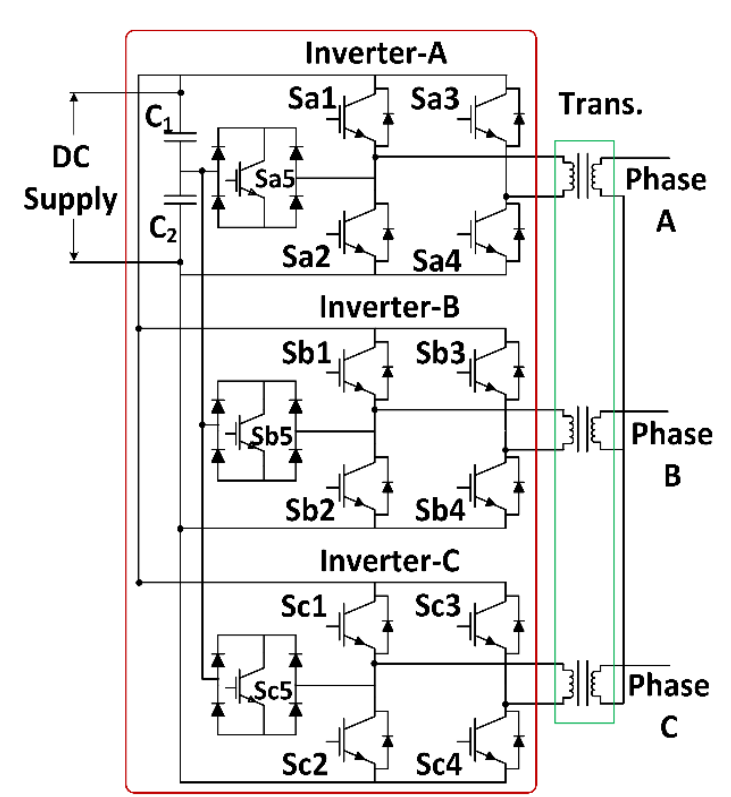

a)

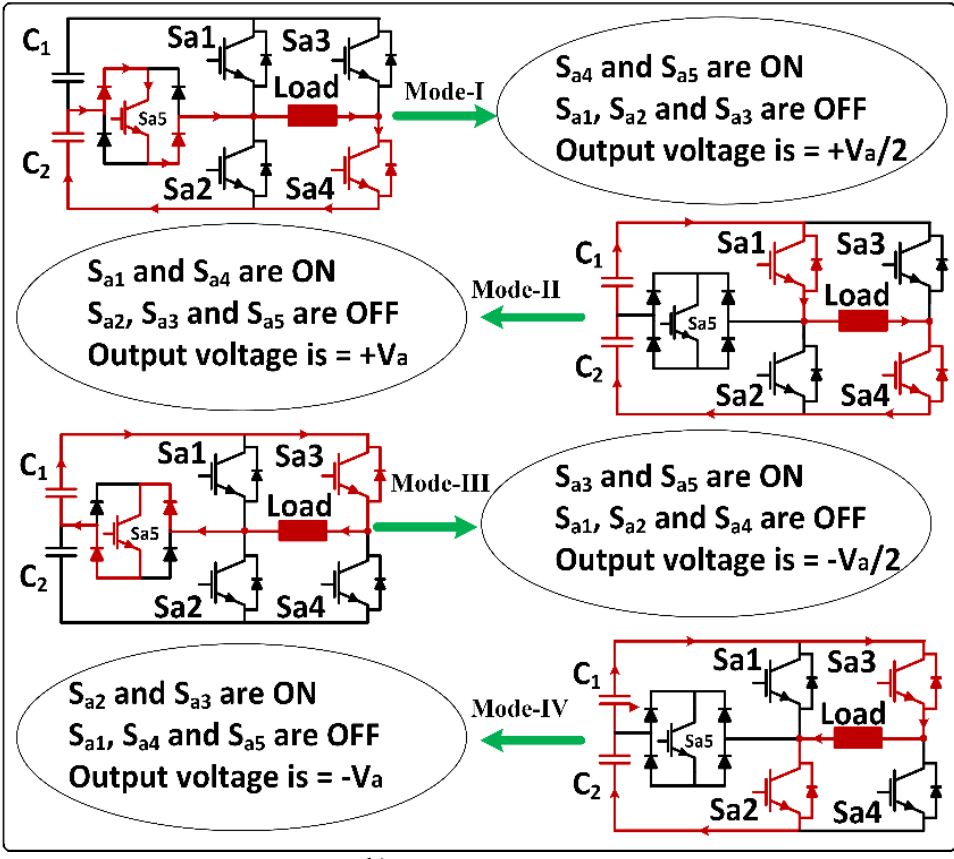

b)

Fig. 2. Modes of operation of the MLI

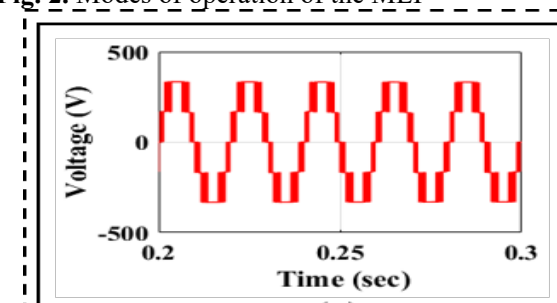

(a)

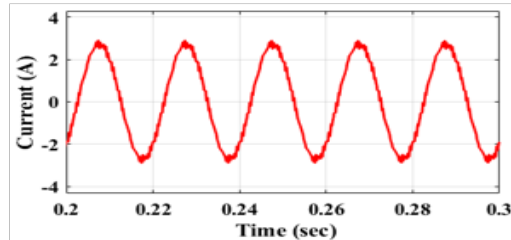

(d)

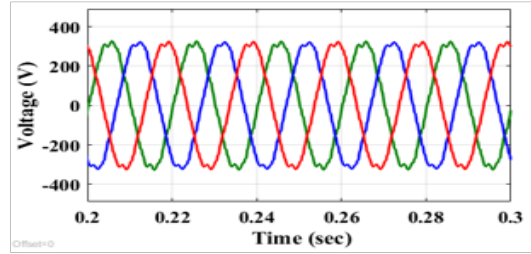

(g)

$\mathrm{MI}=1.1$

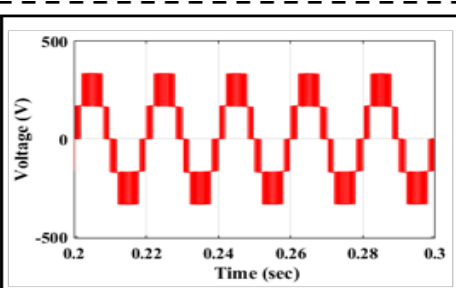

(b)

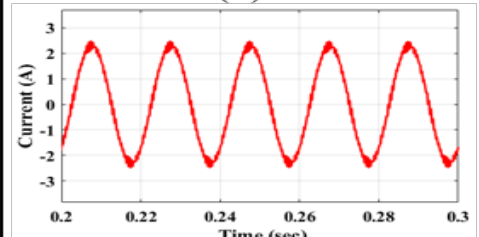

(e)

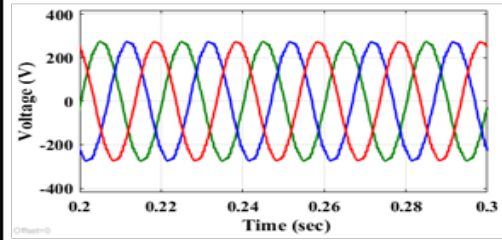

(h)

$\mathrm{MI}=0.7$

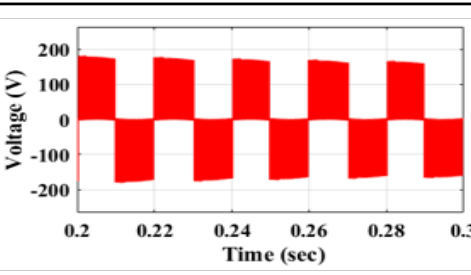

(c)

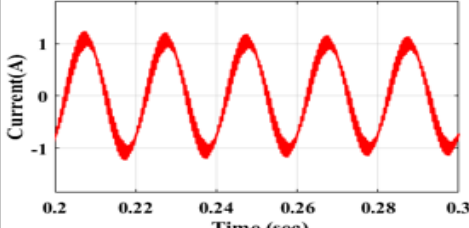

(f)

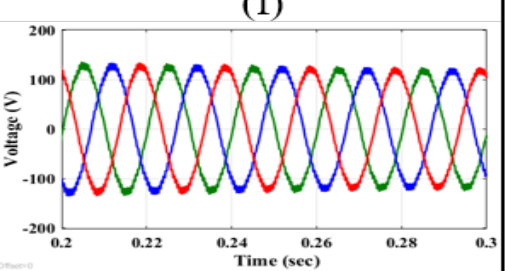

(i)

$\mathrm{MI}=0.4$

Fig. 3. Output voltages and currents of the inverter with various Modulation Index (MI) values 
Table 1. Components required for the suggested topology and existing topologies

\begin{tabular}{|c|c|c|c|}
\hline \multirow{2}{*}{ Components } & \multicolumn{3}{|c|}{ Reference } \\
\hline & {$[5]$} & [11] & Presented \\
\hline Active Switches & 24 & 24 & 15 \\
\hline Input DC Sources & 01 & 01 & 01 \\
\hline DC Bus Capacitors & 01 & 01 & 02 \\
\hline Transformers & 06 & 02 & 01 \\
\hline Total & 32 & 28 & 19 \\
\hline
\end{tabular}

\section{PWM Controllers}

\subsection{Sine PWM (SPWM) Controllers}

The SPWM techniques are the most familiar PWM controller for the regulation of the inverter. The SPWM is classified into two types (i) Phase Shift PWM (PS-PWM) and (ii) Level Shift PWM (LS-PWM). These two controllers are mainly suitable for controlling modular MLIs. In this paper, both PS-PWM and LS PWM are applied to the threephase inverter for controlling the inverter and simulated using MATLAB/Simulink. The switching logic of the LSPWM technique is given in Fig. 4.

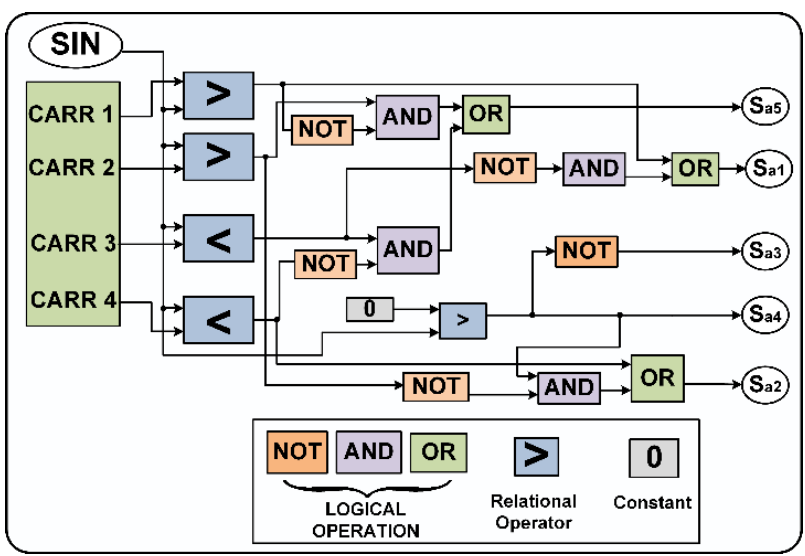

Fig. 4. Switching Logic of LS-PWM (PD)

\subsection{Phase-Shift PWM controller}

In PS-PWM all carriers are maintained at equal amplitude and frequency. For the M-level inverter, M-1 carrier signals are required to generate the switching pulses. Therefore, four carriers are required for the five-level inverter and all carriers are equal magnitudes. In PS-PWM, each carrier maintains a certain phase shift with each other carrier, and The phase shift angle can be calculated using the equation (1) Phase shift angle for the M level inverter is given by

$\mathrm{PS}=360^{\circ} /(\mathrm{M}-1)$

Where; M-number of levels. For the five-level inverter phase shift between each other must be $90^{\circ}$. Fig. 5 represents the Phase shift PWM technique.

\subsection{Level-Shift PWM Controllers}

Another efficient control technique for the inverter is known as LS-PWM. For five-level inverter requires four carrier signals and one reference signal to generate the pulses to the inverter. For the M-level inverter, M-1 carriers to be considered.

$$
M_{i n v}=\frac{A_{m}}{(m-1) A_{c}}
$$

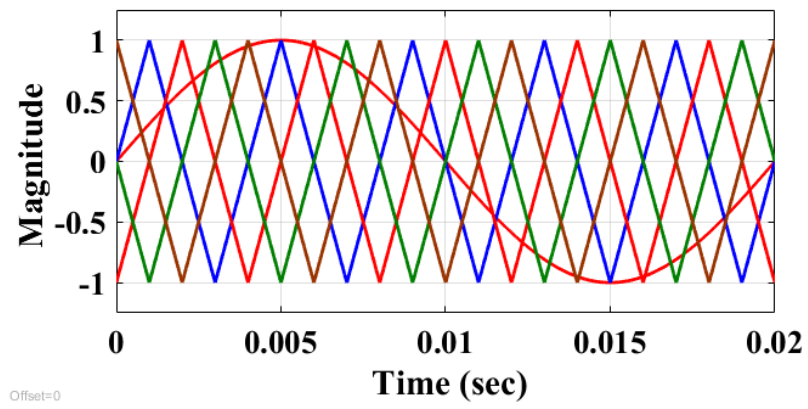

Fig. 5. PS- PWM technique

Where; Am is the amplitude of the reference signal and Ac is the amplitude of the carrier signals. When the amplitude of the reference signal is greater than the carrier signal, then the only pulse was generated for inverter switches. The LSPWM is again classified into three types those are APOD, POD, and PD. Fig. 4 represents the switching logic for the PS-PWM and LS-PWM control techniques. The frequency modulation ratio of the signal is given by

$$
M_{f}=\left(f_{s} / f_{r}\right)
$$

Where; fs-represented the fundamental frequency, frrepresented carrier frequency. In the PD-PWM technique, four carriers are to be considered for pulse generation. Out of four carriers, the upper two carriers are positive from the reference point and the lower two carriers are negative from the reference point. Fig. 6 represents the PD-PWM technique, in this, all carriers are maintaining equal magnitude and phase shift. Fig. 7 represents the POD-PWM technique, in this, all positive carriers are maintaining equal magnitudes and phase shift. But, the negative carriers are maintaining the $180^{\circ}$ phase shift with positive carriers. Fig. 8 represents the APOD-PWM technique, in this, all carriers are maintaining equal magnitude and each carrier maintains a $180^{\circ}$ phase shift with other carriers.

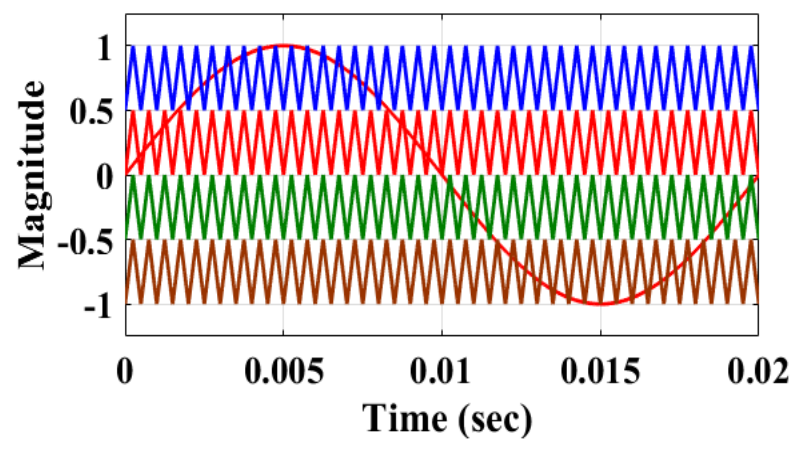

Fig. 6. PD-PWM technique 


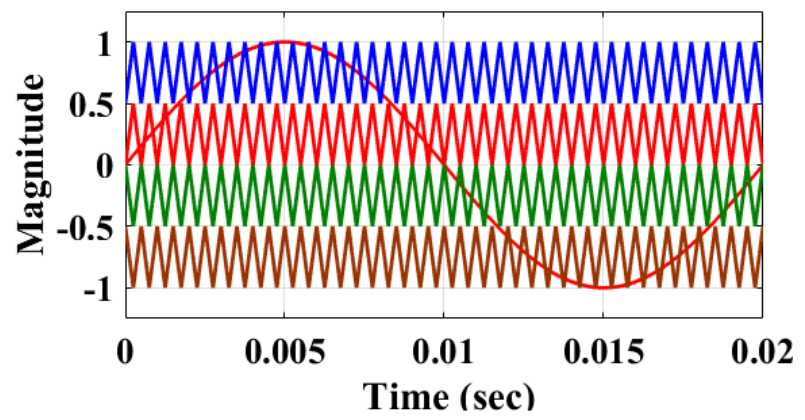

Fig. 7. POD-PWM technique

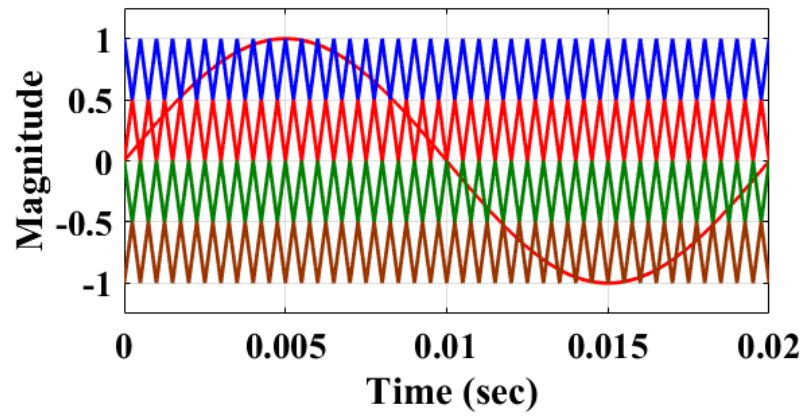

Fig. 8. APOD-PWM

\section{PI current regulators}

In order to control the grid current, a PI current regulator has been used in the work. The block diagram of the closedloop controller is shown in Fig. 9.

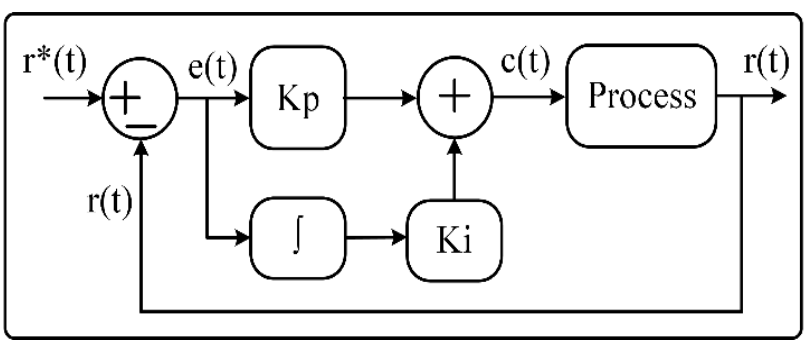

Fig. 9. Block diagram of the PI controller

$$
G_{c}(s)=K_{p}\left(1+\frac{1}{k_{i} S}\right)=K_{p}\left(\frac{k_{i} S+1}{k_{i} S}\right)
$$

From Fig. 9, r*(t) - Reference value, $r(\mathrm{t})$-actual value, and $\mathrm{e}(\mathrm{t})$-error value. The behavior of a three-phase electrical system is given by its voltage and the current equation and coefficients in this differential equation are varying with respect to time. The mathematical modeling of such a system is very difficult. To solve such a problem through transformation techniques. The output side parameters are measured and converted from three-phase quantity to twophase quantity for easy and fast mathematical computation of the electrical parameters. The three-phase quantity is converted into a stationary reference frame and again converted into a synchronously rotating reference frame and it is shown in Fig. 10. The direct and quadrature axis has a fundamental and oscillating component. The transformation angle for the transformation is obtained from the Phase Locked Loop (PLL) in synchronization with the grid voltage. MPPT algorithm measures the grid voltage and current and compares the output with the direct and quadrature component of the grid voltage and current.

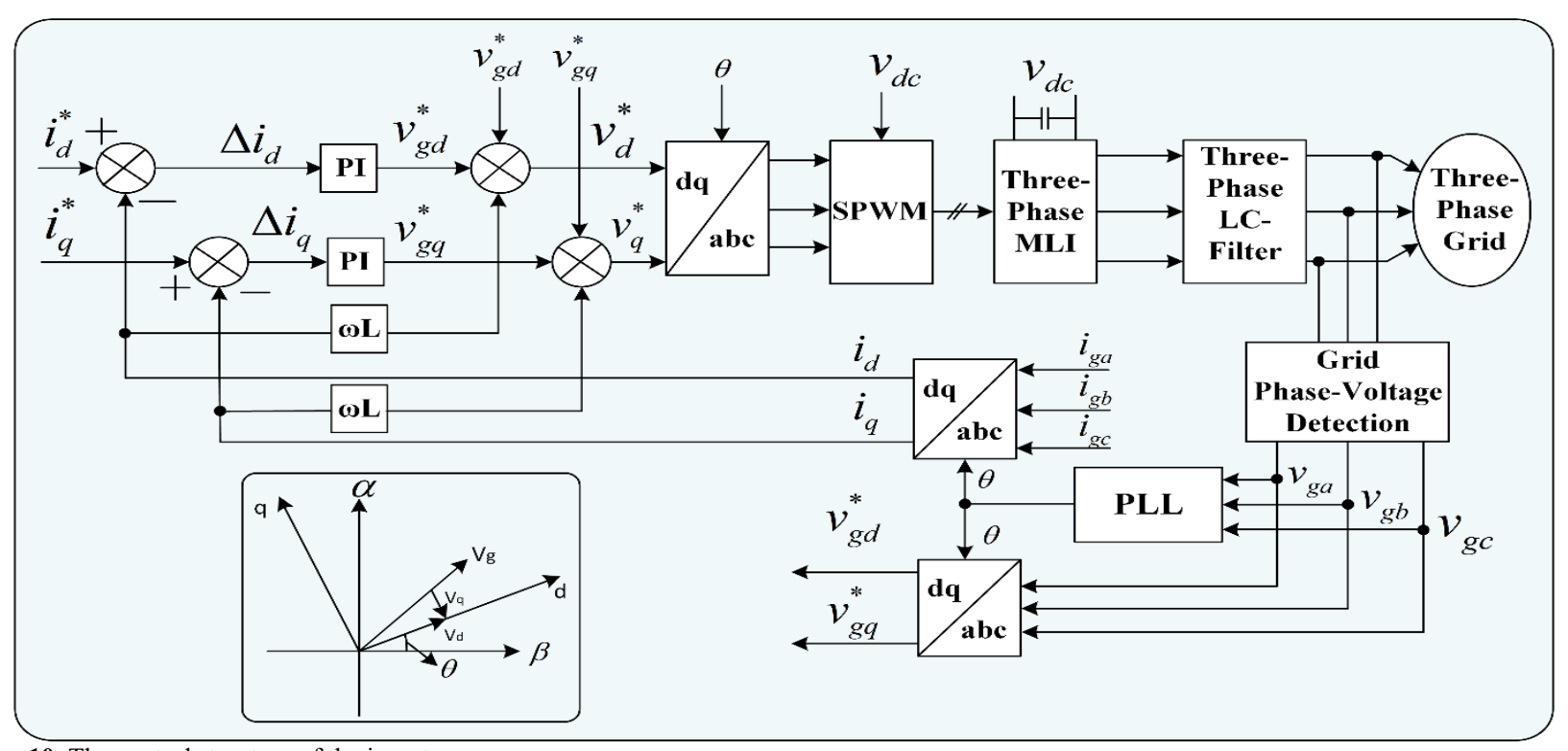

Fig. 10. The control structure of the inverter

The error signal is tuned using a PI controller and the output is given to the inverse Clarke transformation and inverse park transformation to convert the controlled quantity from two axes to three-phase quantity. The dq0-abc converter is used for driving the three-phase five-level inverter from a carrier-based PWM generator

\section{Simulation Results}

In this section, the simulation results of the PWM controller three-phase inverter have been discussed and verified through MATLAB/Simulink. The inverter switches are controlled by SPWM (PS-PWM and LS-PWM) and the PI controller is used to design a current controller for a gridconnected inverter system. Fig. 11 represents the corresponding outputs of the PD-PWM. In Fig. 11(a) represents the phase voltages of the inverter for PD-PWM, Fig. 11(b) represents the three-phase load voltages and load currents of the PD-PWM, Fig. 11(c) represents the THD 
analysis of the inverter by using PD-PWM, by using this technique the inverter produces $1.95 \%$ THD. Fig. 12 represents the corresponding outputs of the POD-PWM. In Fig. 12(a) represents the phase voltages of the inverter for POD-PWM, Fig. 12(b) represents the three-phase load voltages and load currents of the POD-PWM, Fig. 12(c) represents the THD analysis of the inverter by using PODPWM, by using this technique the inverter produces $2.00 \%$ THD. Fig. 13 represents the corresponding outputs of the APOD-PWM. In Fig. 13(a) represents the phase voltages of the inverter for APOD-PWM, Fig. 13(b) represents the three-phase load voltages and load currents of the APODPWM, Fig. 13(c) represents the THD analysis of the inverter by using APOD-PWM, by using this technique the inverter produces $2.09 \%$ THD. Fig. 14 represents the corresponding outputs of the PS-PWM. In Fig. 14(a) represents the phase voltages of the inverter for PS-PWM, Fig. 14(b) represents the three-phase load voltages and load currents of the PSPWM, Fig. 14(c) represents the THD analysis of the inverter by using PS-PWM, by using this technique the inverter produces $2.03 \%$

THD.

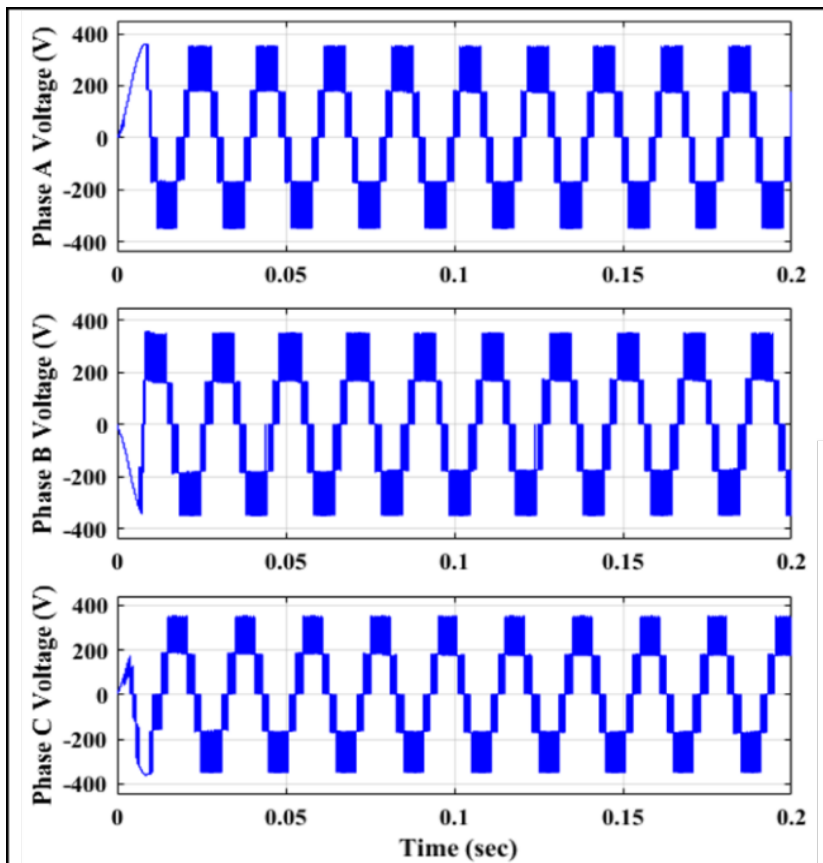

(a)

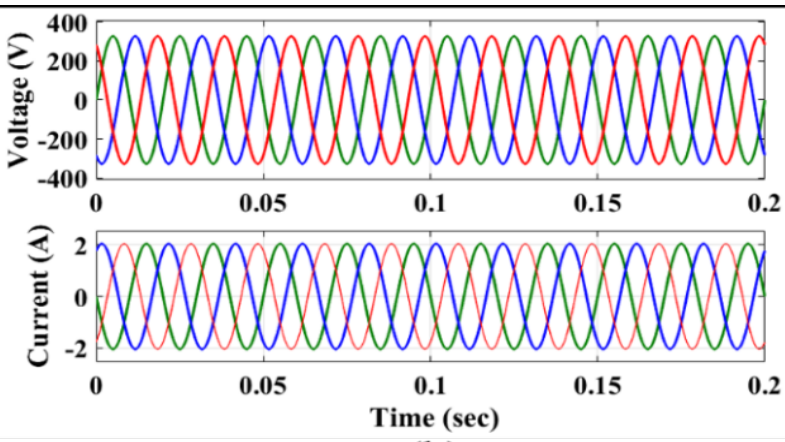

(b)

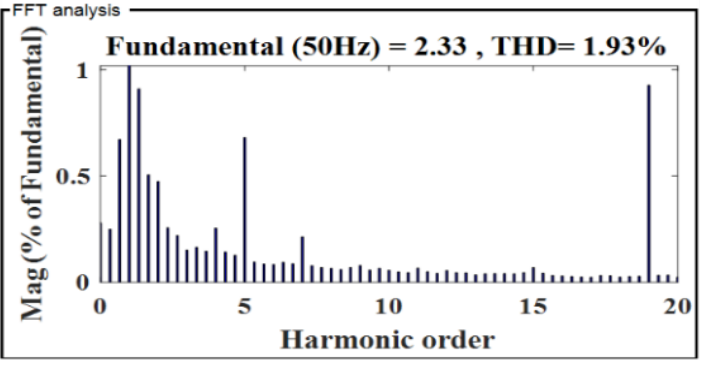

(c)

Fig. 11. PD-PWM Simulation results.
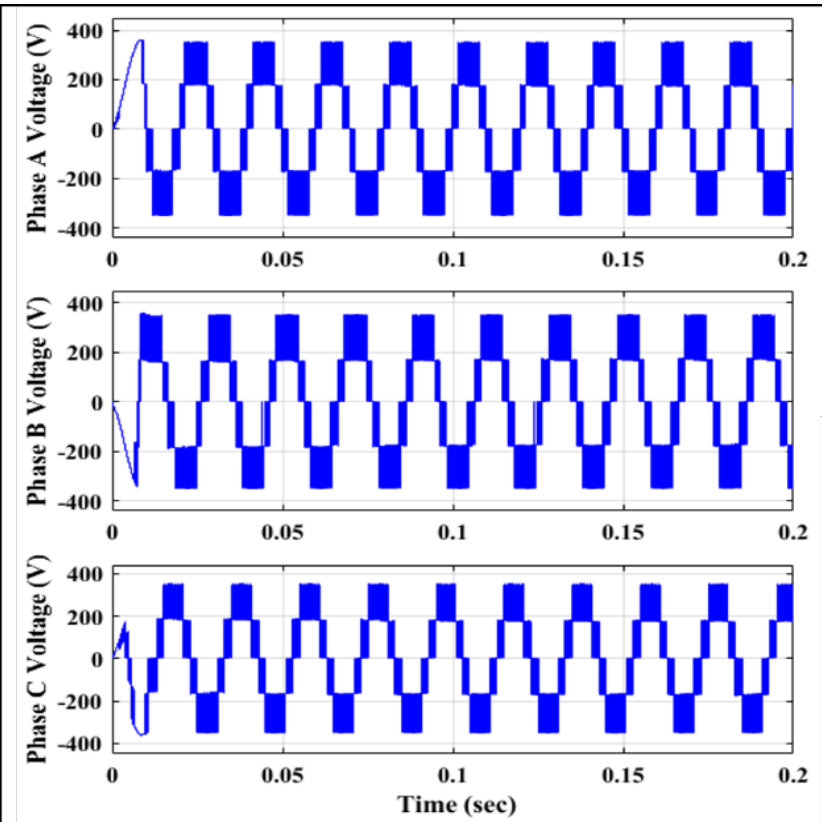

(a)

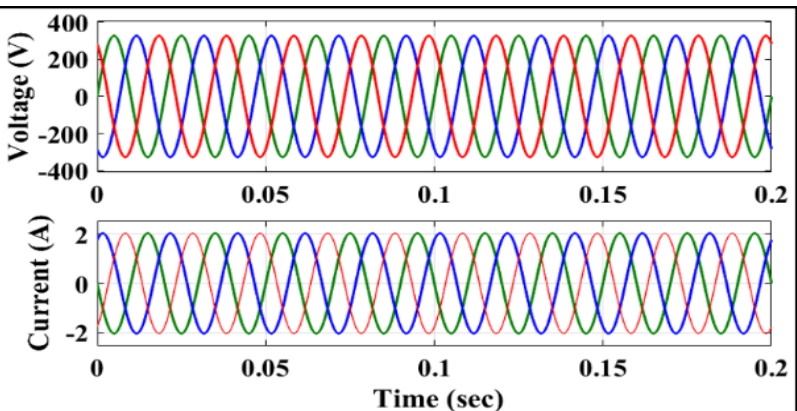

(b)

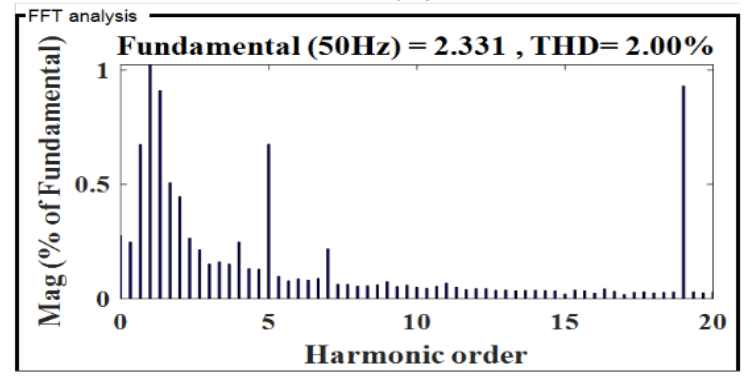

(c)

Fig. 12. POD-PWM simulation results 

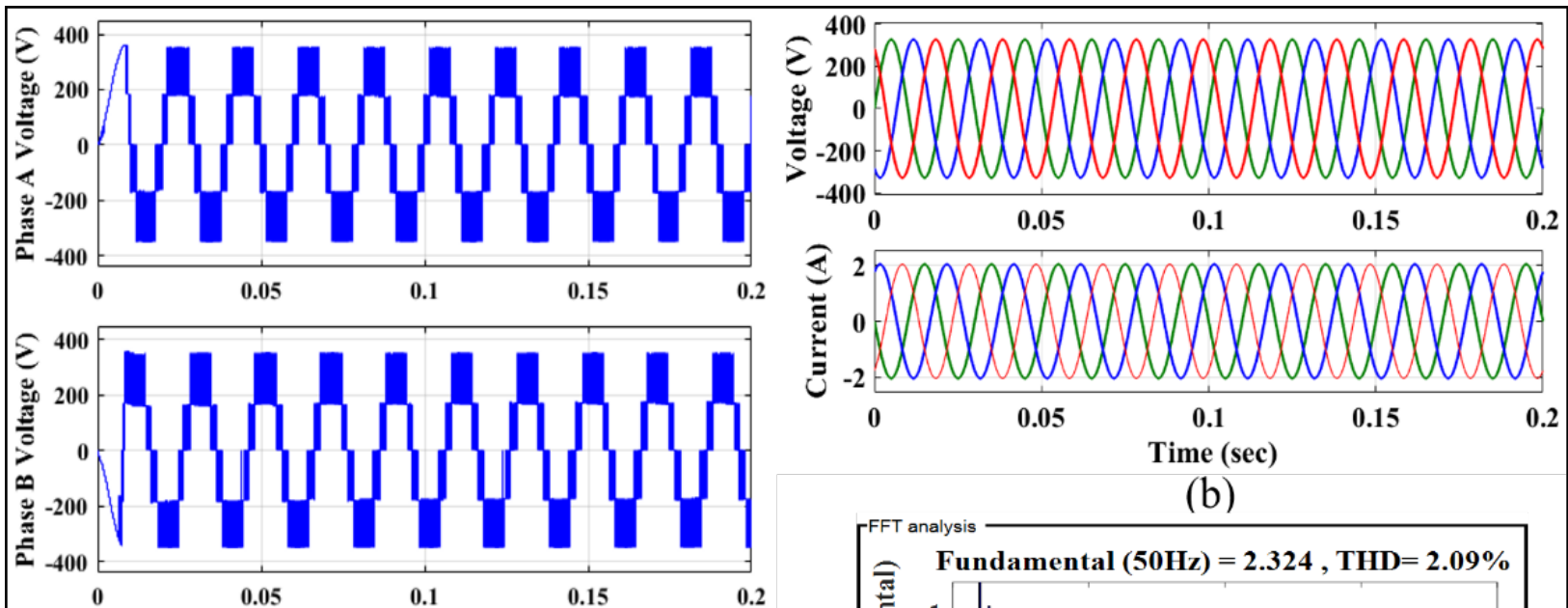

(b)

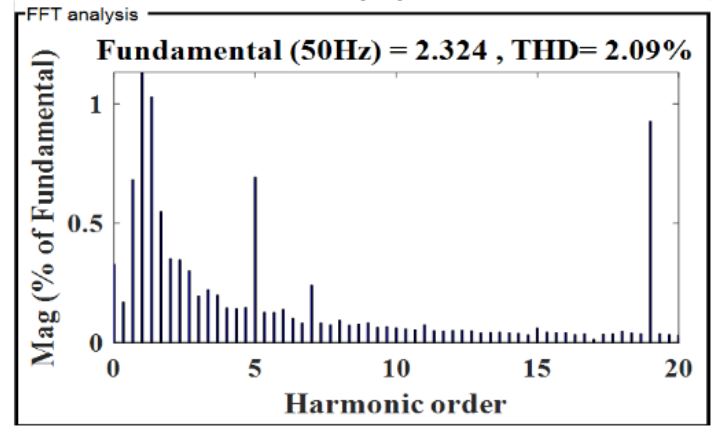

(a)

(c)

Fig. 13. APOD-PWM Simulation results.
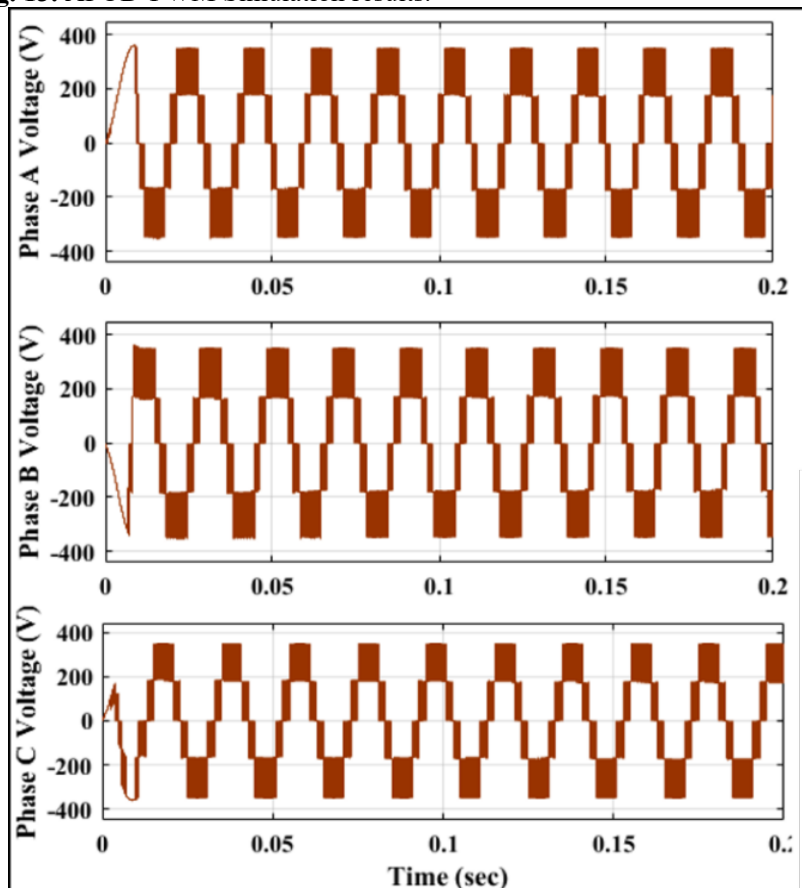

(a)

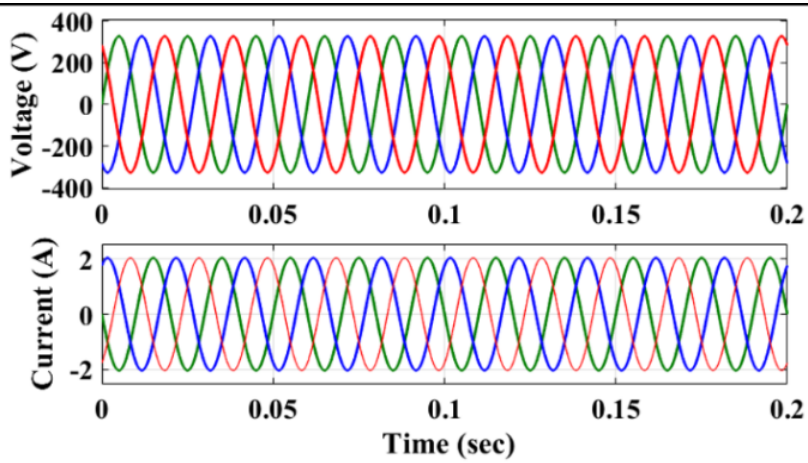

(b)

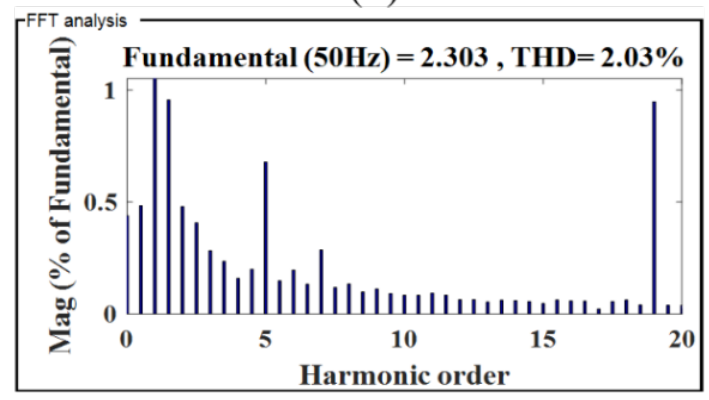

(c)

Fig. 14. PS-PWM Simulation results.

The proposed PWM controlled three-phase system has produced $1.93 \%$ of THD using an LS PWM technique whereas $2.03 \%$ of THD using PS PWM techniques in Table 2.

Table 2. Comparison of $\%$ THD with the proposed system and existing systems

\begin{tabular}{ccc}
\hline Reference & \%THD & PWM technique \\
\hline$[2]$ & 2.84 & PWM \\
{$[6]$} & 5.69 & LS-PWM \\
\hline
\end{tabular}

\begin{tabular}{ccc}
\hline$[7]$ & 2.43 & LS-PWM \\
{$[9]$} & 4.16 & SPWM \\
{$[15]$} & 3.56 & LS-PWM \\
Proposed & 1.93 & LS-PWM \\
Proposed & 2.03 & PS-PWM \\
\hline
\end{tabular}


\% THD

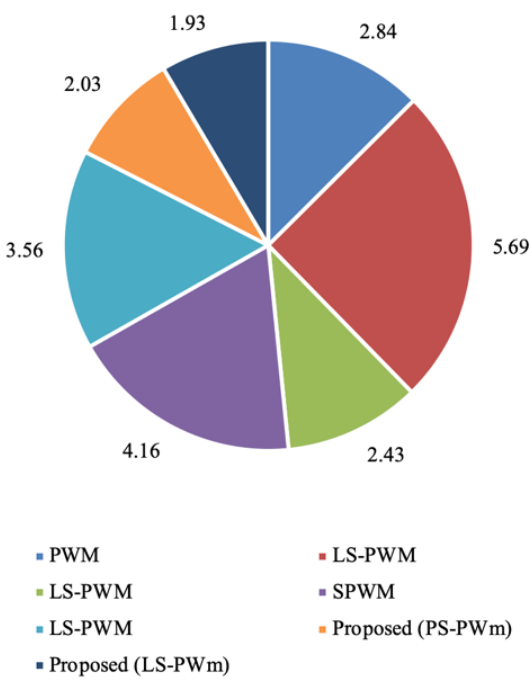

\section{Conclusion}

A three-phase grid-connected inverter using different PWM controllers has been investigated in this article. The PI current control regulator has been applied to control the grid current. The inverter switches are controlled by SPWM techniques. In this observe the framework execution regarding THD and the proposed current controller generated less THD when contrasted with the current strategies. The proposed system with the PI controller produces $1.93 \%$ THD, the produced THD is within the IEE standards. The entire work is done in MATLAB/Simulink tool.

This is an Open Access article distributed under the terms of the Creative Commons Attribution License

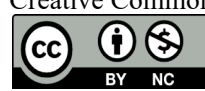

Fig. 15. Flow chart of \% THD with the proposed system and existing system

\section{References}

1. R. K. Kalilasam, V. Mani, "FPGA based quasi z-source cascaded multilevel inverter using multicarrier PWM techniques," Journal of Vibroengineering, 20(3), pp. 1544-1553, (2018).

2. R. Gunasekaran, C. Karthikeyan, "Nonlinear Transformational Optimization (NTO) Technique Based Total Harmonics Distortion (THD) Reduction of Line To Line Voltage For Multi-Level Inverters," Microprocessors and Microsystems, 74, (2020).

3. P. Kala, S. Arora, "A comprehensive study of classical and hybrid multilevel inverter topologies for renewable energy applications," Renewable and Sustainable Energy Reviews, 76, pp. 905-931, (2017).

4. V. Mani, R. Ramachandran, D. Nanjundappan, "Implementation of a modified SVPWM-based three-phase inverter with reduced switches using a single DC source for a grid-connected PV system," Turkish Journal of Electrical Engineering \& Computer Sciences, 24(4), pp. 3023-3035, (2016).

5. K. Panda, Y. Suresh, "Performance of cascaded multilevel Inverter by employing single and three-phase transformers," IET Power Electron 5(9), pp. 1694-1705, (2012).

6. J. Kavali, A. Mittal, "Analysis of various control schemes for minimal Total Harmonic Distortion in cascaded H-bridge multilevel inverter," Journal of Electrical Systems and Information Technology 3, pp. 428-441, (2016).

7. M. Tariq, M. Meraj, A. Azeem, A. I. Maswood, A. Iqbal, B. Chokkalingam, "Evaluation of Level-Shifted and Phase-Shifted PWM Schemes for Seven Level Single-Phase Packed U Cell Inverter," CPSS Transactions on Power Electronics and Applications, 3(3), (2018).
8. S. Rajalakshmi, P. Rangarajan, "Investigation of Modified Multilevel Inverter Topology for PV System," Microprocessors and Microsystems, 71, pp. 1-14, (2019).

9. Colak, E. Kabalci, R. Bayindir, "Review of multilevel voltage source inverter topologies and control schemes," Energy Conversion and Management, 52(2), pp. 1114-1128, (2011).

10. A. Harbi, H. Z. Azazi, A. E. Lashine, A. E. Elsabbe, ":A higher levels multilevel inverter with reduced number of switches," International Journal of Electronics, 105(8), pp. 1286-1299, (2018).

11. Venkataramanaiah, Y. Suresh, A. K. Panda, "A review on symmetric, asymmetric, hybrid and single DC sources based multilevel inverter topologies," Renewable and Sustainable Energy Reviews 76, pp. 788-812, (2017).

12. Y. Suresh, A. K. Panda, "Investigation on hybrid cascaded multilevel inverter with reduced dc sources," Renewable and Sustainable Energy Reviews 26, pp. 49-59, (2013).

13. S. Ranjeeth, T. P. Latchoumi, P. V. Paul, "Optimal Stochastic Gradient Descent with Multilayer Perceptron Based Student's Academic Performance Prediction Model," Recent Advances in Computer Science and Communications 13: 1, (2020).

14. Sinha, K. C. Jana, M. K. Das, "An inclusive review on different multi-level inverter topologies their modulation and control strategies for a grid connected photo-voltaic system," Solar Energy, 170, pp. 633-657, (2018).

15. T. A. Ahmed, E. E. M. Mohamed, A. R. Youssef, A. A. brahim, M. S. R. Saeed A. I. M. Ali, "Three phase modular multilevel inverterbased multi-terminal asymmetrical DC inputs for renewable energy applications," Engineering Science and Technology, an International Journal, (2020). 